\title{
The Effects of Efficiency, Design and Enjoyment on Single Platform E-payment
}

\author{
PC Lai (Corresponding Author) \\ Help University \\ E-mail: pcresearch8@gmail.com
}

Chui Seong Lim

Help University

Received: April 27, 2019

Accepted: July 15, 2019

Published: August 20, 2019

doi:10.5296/rbm.v6i2.15306

URL: http://dx.doi.org/10.5296/rbm.v6i2.15306

\begin{abstract}
This paper summarizes an explorative study of the efficiency, design, and enjoyment that contribute to consumers' adoption of an integrated single platform E-payment system. The problems of inefficiency, not attractive design and not enjoyable encourages us to study these factors. The empirical results from the quantitative analysis suggest that efficiency, design, enjoyment, perceived usefulness, as well as perceived ease of use, are significant factors that contribute to consumers' intention to utilize the single platform E-payment. Marketing and Management personnel of the E-payment organizations will be able to utilize the study information for developing products and services that encourage the usage of single platform E-payment.
\end{abstract}

\section{Introduction}

There is a concern of current e-payment solution in providing a good design, an efficient and enjoyable way for E-payment transaction (Meuter, Ostrom, Roundtree, and Bitner, 2000; Lai, 2007, Alkibsi and Lind, 2011; Lai, 2014; Lai, 2016). E-payment has been around but the usage is not as high as expected due to problems of inefficiency, not attractive design and not enjoyable. Therefore, organizations providing E-payment solutions are looking at the efficiency, design and enjoyment single platform e-payment to encourage usage of E-payment. This has given us the opportunity to study the effects of efficiency, design, and enjoyment that will encourage the use of single platform E-payment.

\subsection{Technology Acceptance Model}

Technology Acceptance Model (TAM) which established based on the Theory of Reasoned Action, was first introduced by Fred Davis in 1986. The model aims to provide an understanding of information technology acceptance and pertinent domains of 
human-computer interactions (Davis et al., 1986). In TAM, two beliefs, namely perceived usefulness and perceived ease of use was proposed to be the key predictors for behavioural intention towards information technology (Davis et al., 1989), and perceived ease of use affects perceived usefulness (Venkatesh \& Davis, 2000). Perceived usefulness is defined as the extent to which an individual believes that his or her job performance will be enhanced through particular system use, and perceived ease of use refers to the extent which an individual believes that using the system will be free of effort (Davis et al., 1989).

To date, TAM has emerged as one of the most employed model in new information technology acceptance research, such as e-payment (Lai, 2017), e-commerce (Qiu, \& Li, 2008), online learning (Park et al., 2009) and instant messaging (Lu et al., 2009). Besides perceived usefulness and perceived ease of use, other external variables do play important roles in enhancing the explanatory power of TAM (Venkatesh \& Davis, 2000; Moon \& Kim, 2001). It was posited that external variables influence perceived usefulness and perceived ease of use directly and perceived ease of use and perceived usefulness mediate the technology acceptance (Chang et al., 2012). Opposed to the initial TAM model, attitude is not considered in this study due to its discounted role from previous literature (Taylor \& Todd, 1995; Jackson et al., 1997; Riemenschneider et al., 2003: Lai, 2014; Lai 2016). This study relooks into TAM model in e-payment context by focusing on the external variables, namely efficiency, design, and enjoyment.

\subsection{Efficiency}

Consumers' expectation of efficiency will be based on fast, reliable and guaranteed operations of Single platform e-payment offerings (Lai, 2014). Devaraj, Fan, and Kohli (2002) acknowledged that perceived ease of use and usefulness included factors of time-saving and price saving that were major measures of the efficiency for Internet retail transactions. Phan and Diam (2011) used efficiency as one of the factors for perceived usefulness in the study of mobile phone services that the consumers' intention to use

\subsection{Design}

Szymanski and Hise (2000) and Lai (2016) found that the easier the design of the site for online navigation that led purchase and E-payment, the higher the attraction of consumers towards using the online site design. Belanger, Janine, and Wanda (2000) and McKnight, Vivek, and Charles (2002) concluded that the impact of online shopping site design will influence the consumers' intention to use online shopping. Ahn, Ryu, and Han (2004) discovered that design, navigation and response time had a positive impact on consumers' intention to use online shopping through perceived ease of use and perceived usefulness.

\subsection{Enjoyment}

New information technology like single platform E-payment has provided consumers with personal enjoyment and becomes one of the hottest elements for decision making in consumers. Lai (2014) found that enjoyment has no significant relationship with perceived ease of use. Therefore, in this study enjoyment and perceived ease of use relationship has been dropped. Phan and Diam (2011) used enjoyment as one of the factors for perceived 


\section{Macrothink Institute ${ }^{\mathrm{TM}}$}

usefulness in the study of mobile phone services and found that the consumers' intention to use mobile services was positively related to enjoyment. Furthermore, Ramayah, and Ignatius, (2005) only measured the direct relationship of enjoyment with online shoppers' intention to use. Thus, in this research, we will only study the relationship between enjoyment and perceived usefulness as well as enjoyment and consumers' intention to use.

\subsection{Hypothesis}

This study draws upon adapting TAM by adding security in this research framework suited for consumers' intention to use the Internet and mobile E-Payment and gamification. This study will use the underlining variables shown in Figure 1 to determine the consumers' intention to use the Internet and mobile E-Payment with the presence of incentives or gamification. According to Lai (2016), the design, convenience, and enjoyment are the stimuli that represent the system and features capabilities while the perceived ease of use and perceived usefulness are the organism that represents the motivation to use the system that leads to consumers' respond to using the system. The literature review of technology adoption models and theories for the novelty technology did the comparison of the technologies models and the justification of the use of stimulus research theoretical framework (Lai, 2017:2018) that can be adapted as shown in Figure 1.

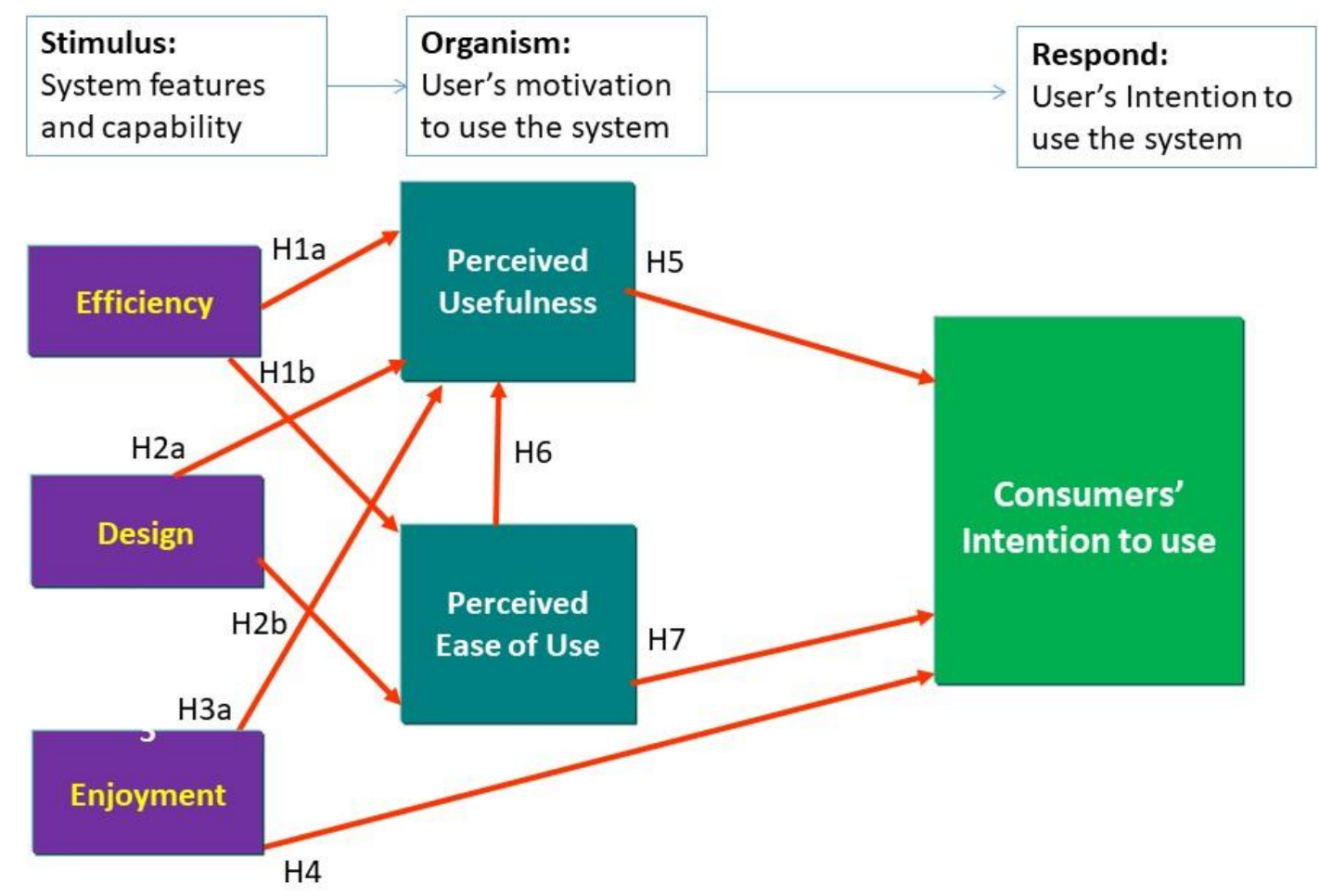

Figure1. Research framework

This study used the underlining variables shown in Figure 1 to determine the consumers' intention to use single platform e-payment. For the purpose of the study, the following hypotheses were posited: 
H1a: Efficiency is positively associated with perceived usefulness.

H1b: Efficiency is positively associated with perceived ease of use.

H2a: Design is positively associated with perceived usefulness.

$\mathrm{H} 2 \mathrm{~b}$ : Design is positively associated with perceived ease of use.

H3a: Enjoyment is positively associated with perceived usefulness.

H4: Enjoyment is positively associated with consumers' intention to use

H5: Perceived usefulness is positively associated with consumers' intention to use

H6: Perceived ease of use is positively associated with perceived usefulness.

H7: Perceived ease of use is positively associated with consumers' intention to use

\section{Research Method}

\subsection{Sample and data}

Based on the research framework and the study's hypotheses, this study applied online survey questionnaire as a data collection method and non-probability sampling method was used. The targeted respondents were consumers who have experience in purchasing goods or services online for the last 1 year from the Malaysian users. A total of 455 useable responds were collected, exceeded the minimum sample size requirement of 200 suggested by Hair et al. (2009). Table 1 summarized the demographic profiles of the respondents.

\subsection{Data Analysis}

The data analysis was conducted in two stages using SPSS and SmartPLS. Respondents' answers were carefully keyed and entered into SPSS (Statistical Package for Social Science version 24) and screen for missing values and cleaned. In the preliminary data analysis using SPSS, data was then inspected and explored to get the descriptive statistics and frequency distributions. This is then followed by examining the presence of univariate and multivariate outliers, the violation of normality, correlation, and multicollinearity. The set of data then proceeded to SmartPLS for the main analysis and hypothesis testing.

Some core advantages of PLS-SEM is that it can deal with small sample size, able to handle complex causal models, does not require data multivariate normality, uses latent variables for subsequent analysis and suitable for predictive research goals (Hackman 2006, Hair et al 2011, Urbach \& Ahleman, 2010). Based on the discussed advantages of PLS over CB-SEM, PLS modelling was used because this present study objective is a prediction, and can handle any constructs that are slightly skewed (not normally distributed).

PLS analysis consists of an assessment of the measurement model (outer model) and inner model (structural model). The outer model is to examine the reliability and validity of the measures according to model specification and the inner model is to assess the structural model estimation (Hair et al 2011). Outer relation modelling relations between observed indicators and latent variables, and inner relations or structural paths represent the 


\section{Macrothink MInstitute ${ }^{\text {tm }}$}

relationship amongst the latent constructs (Mandhachitara \& Poolthong 2011). Procedures in analyzing measurement and structural models suggested by Hair et al (2014) were followed. Hence SmartPLS used to generate the measurement model and follow by a structural model. The evaluation of the reflective measurement model includes assessment of reliability and validity of the latent variables (Hair, Hult, Ringle \& Sarstedt 2016). This is then followed by assessing the structural model which concerned with the relationship between the latent variables.

Table 1 Demographic and Characteristic Profile

\begin{tabular}{|c|c|c|}
\hline Demographic & Frequency & Percentage $(\%)$ \\
\hline \multicolumn{3}{|l|}{ Gender } \\
\hline Male & 249 & 54.7 \\
\hline Female & 206 & 45.3 \\
\hline \multicolumn{3}{|l|}{ Age } \\
\hline 25 and Below & 152 & 33.4 \\
\hline $26-40$ & 182 & 40.0 \\
\hline $41-55$ & 105 & 23.1 \\
\hline 56 and Above & 16 & 3.5 \\
\hline \multicolumn{3}{|l|}{ Marital Status } \\
\hline Single & 248 & 54.5 \\
\hline Married & 207 & 45.5 \\
\hline \multicolumn{3}{|l|}{ Education } \\
\hline Secondary/ High School & 117 & 25.7 \\
\hline College/ University & 268 & 58.9 \\
\hline Graduate School & 70 & 15.4 \\
\hline \multicolumn{3}{|l|}{ Industry Work in } \\
\hline Education & 189 & 41.5 \\
\hline Banking/ Finance & 39 & 8.6 \\
\hline Retail/ Hypermarket & 41 & 9.0 \\
\hline Manufacturing/ ICT & 139 & 30.5 \\
\hline Other & 47 & 10.3 \\
\hline \multicolumn{3}{|l|}{ Job Position } \\
\hline Top Management & 20 & 4.4 \\
\hline Middle Management & 155 & 34.1 \\
\hline Junior Management & 43 & 9.5 \\
\hline Professional & 55 & 12.1 \\
\hline Other & 182 & 40.0 \\
\hline \multicolumn{3}{|c|}{ Interest in single platform E-payment } \\
\hline Strongly Interested & 240 & 52.7 \\
\hline Interested & 10 & 2.2 \\
\hline Neutral & 174 & 38.2 \\
\hline Not Interested & 27 & 5.9 \\
\hline Strongly Not Interested & 4 & .9 \\
\hline
\end{tabular}




\subsection{Results of Measurement Model}

Table A: Result of Measurement Model

\begin{tabular}{|c|c|c|c|c|}
\hline & Loadings & $\begin{array}{l}\text { CR ( composite } \\
\text { Reliability) }\end{array}$ & $\begin{array}{l}\text { Cronbach's } \\
\text { Alpha }\end{array}$ & $\begin{array}{l}\text { AVE ( Average } \\
\text { Variance } \\
\text { Extracted) }\end{array}$ \\
\hline CI1 & 0.811 & 0.908 & 0.866 & 0.712 \\
\hline $\mathrm{CI2}$ & 0.876 & & & \\
\hline CI3 & 0.851 & & & \\
\hline CI4 & 0.838 & & & \\
\hline D3 & 0.931 & 0.983 & 0.979 & 0.905 \\
\hline D4 & 0.924 & & & \\
\hline D5 & 0.966 & & & \\
\hline D6 & 0.964 & & & \\
\hline D7 & 0.963 & & & \\
\hline D8 & 0.959 & & & \\
\hline E2 & 0.832 & 0.915 & 0.945 & 0.684 \\
\hline E3 & 0.790 & & & \\
\hline E4 & 0.673 & & & \\
\hline E5 & 0.900 & & & \\
\hline E6 & 0.917 & & & \\
\hline EF3 & 0.885 & 0.960 & 0.950 & 0.858 \\
\hline EF4 & 0.939 & & & \\
\hline EF5 & 0.928 & & & \\
\hline EF6 & 0.952 & & & \\
\hline PEU2 & 0.889 & 0.975 & 0.970 & 0.828 \\
\hline PEU3 & 0.921 & & & \\
\hline PEU4 & 0.908 & & & \\
\hline PEU5 & 0.927 & & & \\
\hline PEU6 & 0.905 & & & \\
\hline PEU7 & 0.907 & & & \\
\hline PEU8 & 0.913 & & & \\
\hline PEU9 & 0.911 & & & \\
\hline PU1 & 0.863 & 0.959 & 0.887 & 0.770 \\
\hline PU2 & 0.859 & & & \\
\hline PU3 & 0.884 & & & \\
\hline PU4 & 0.908 & & & \\
\hline PU5 & 0.923 & & & \\
\hline PU6 & $\mathbf{0 . 8 8 7}$ & & & \\
\hline PU7 & 0.816 & & & \\
\hline
\end{tabular}

Note: $\mathrm{CI}=$ customer intention to use one payment system, D=Design, EF=Efficiency, E=Enjoyment, PEU=Perceived Ease of Use, and PU= Perceived Usefulness 
The measurement model was generated using PLS-SEM algorithm in SmartPLS. The first criterion to be evaluated was indicator reliability and then followed by internal consistency reliability. Reflective indicators should be eliminated if they fall below 0.7 (Sarstedt, Ringle, Smith \& Reams 2014) or smaller than 0.4 (Hulland 1999). The final outer loadings shown in Table A. One indicator falls slightly below 0.7 and consideration for removal if it helps to improve the reliability. All constructs are having AVE (Average Variance Extracted) values above the cut off value of 0.5 (Henseler, Ringle \& Sinkovics, 2009; Hair et al. 2013). The Composite reliability (CR) and Cronbach's alpha values of all constructs were found to be an above-suggested threshold value of 0.7 ( Henseler et al 2009, Hair et al 2014). These results indicate that the constructs possess adequate internal consistency and validity hence, no items were further deleted. Hence the analysis proceeds to the evaluation of discriminant validity.

\subsection{Discriminant Validity}

Table B: Discriminant Validity

\begin{tabular}{|l|l|l|l|l|l|l|}
\hline & CI & Design & EF & PU & PEU & E \\
\hline $\begin{array}{l}\text { Customer intention to use } \\
\text { one payment system (CI) }\end{array}$ & $\mathbf{0 . 8 4 4}$ & & & & & \\
\hline Design (D) & 0.590 & $\mathbf{0 . 9 5 1}$ & & & & \\
\hline Efficiency (EF) & 0.575 & 0.812 & $\mathbf{0 . 9 2 6}$ & & & \\
\hline Perceived Usefulness (PU) & 0.643 & 0.807 & 0.796 & $\mathbf{0 . 8 7 8}$ & & \\
\hline Perceived Ease of Use (PEU) & 0.603 & 0.737 & 0.774 & 0.829 & $\mathbf{0 . 9 1 0}$ & \\
\hline Enjoyment (E) & 0.591 & 0.603 & 0.642 & 0.612 & 0.484 & 0.827 \\
\hline
\end{tabular}

Note: The Square root of AVEs shown diagonally in bold.

To assess the discriminant validity, Fornell-Larcker criterion is used to evaluate (Mackenzie, Podsakoff \& Podsakoff 2011) and requires that the square root of AVE value of each construct should be greater than its highest correlations with any other construct (Hair et al. 2014). Table B shows all constructs having higher AVE square root value (in bold) than its correlations with other constructs in the model.

Recent studies suggested that HTMT can be used to evaluate constructs discriminant validity (Henseler, Ringle \& Sarstedt 2015). Table C showed all the values were found to be above 0.9 as suggested by Hair et al (2017).

Hence, the constructs' discriminant validity are adequate with Fornell-Larcker criterion and HTMT. Following established reliable and valid measurement models, the next phase was to assess the structural model. 
Table C: Heterotrait-Monotrait Ratio (HTMT)

\begin{tabular}{|l|l|l|l|l|l|}
\hline & CI & Design & EF & PU & PEU \\
\hline CI & & & & & \\
\hline Design & 0.636 & & & & \\
\hline EF & $\mathbf{0 . 6 2 7}$ & $\mathbf{0 . 8 4 4}$ & & & \\
\hline PU & $\mathbf{0 . 7 0 0}$ & $\mathbf{0 . 8 3 6}$ & $\mathbf{0 . 8 4 0}$ & & \\
\hline PEU & $\mathbf{0 . 6 4 6}$ & $\mathbf{0 . 7 5 5}$ & $\mathbf{0 . 8 0 8}$ & 0.863 & \\
\hline Enjoyment & $\mathbf{0 . 6 5 5}$ & $\mathbf{0 . 6 1 4}$ & $\mathbf{0 . 6 5 9}$ & $\mathbf{0 . 6 2 5}$ & $\mathbf{0 . 4 6 5}$ \\
\hline
\end{tabular}

Note: $\mathrm{CI}=$ customer intention to use one payment system, $\mathrm{D}=\mathrm{Design}, \mathrm{EF}=\mathrm{Efficiency}$, E=Enjoyment, PEU=Perceived Ease of Use, and PU= Perceived Usefulness

\subsection{Results of Structural Model}

The structural model was produced using the bootstrapping procedure in SmartPLS. It was run with bootstrapping on 500 subsamples for the 455 cases. Figure A shows the summary results of the structural model analysis. The structural relationships represent the hypotheses relationship amongst the constructs (Hair et al 2017). Critical values of path coefficient with the one-tailed test are 1.65 and 2.33 at $5 \%$ and $1 \%$ significant levels respectively. Table D shown that all hypothesis is supported.

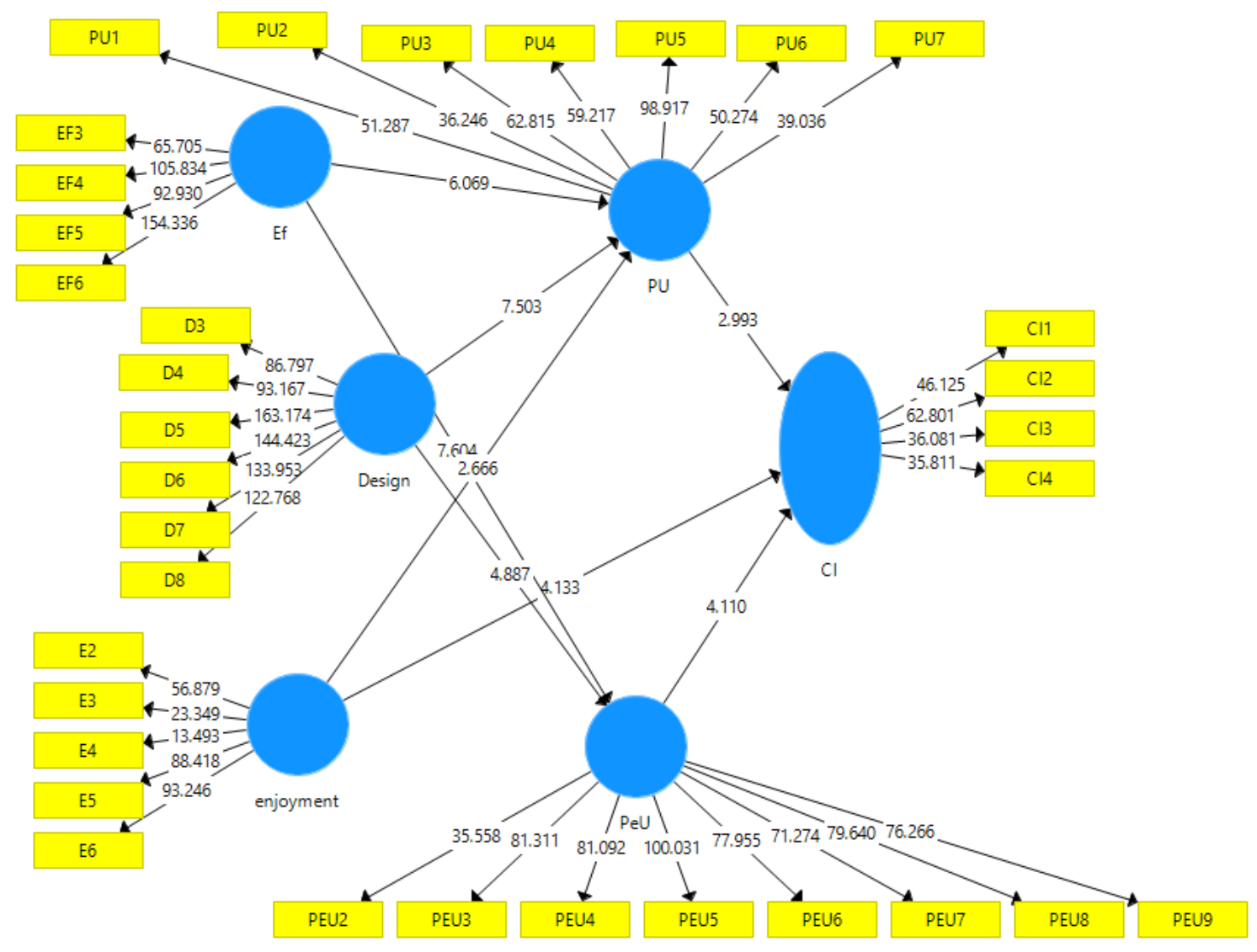

Figure 1 Results of Structural Model 
Table D Results of Hypothesis Testing

\begin{tabular}{|l|l|l|l|l|l|}
\hline & $\begin{array}{l}\text { Path } \\
\text { Coefficient }\end{array}$ & T-values & $\begin{array}{l}\text { P } \\
\text { Values }\end{array}$ & $\begin{array}{l}95 \% \\
\text { Confidence } \\
\text { interval }\end{array}$ & Supported \\
\hline Design -> PU & 0.450 & 7.503 & 0.000 & $0.332-0.562$ & Yes \\
\hline Design -> PEU & 0.318 & 4.887 & 0.000 & $0.192-0.462$ & Yes \\
\hline EF -> PU & 0.364 & 6.069 & 0.000 & $0.245-0.475$ & Yes \\
\hline EF-> PEU & 0.516 & 7.604 & 0.000 & $0.371-0.638$ & Yes \\
\hline PU -> CI & 0.239 & 2.993 & 0.003 & $0.082-0.392$ & Yes \\
\hline PEU -> CI & 0.248 & 4.110 & 0.000 & $0.134-0.366$ & Yes \\
\hline E -> CI & 0.325 & 4.133 & 0.000 & $0.160-0.450$ & Yes \\
\hline E-> PU & 0.109 & 2.666 & 0.008 & $0.034-0.184$ & Yes \\
\hline
\end{tabular}

Note: $\mathrm{CI}=$ customer intention to use one payment system, D=Design, EF=Efficiency, $\mathrm{E}=$ Enjoyment, $\mathrm{PEU}=$ Perceived Ease of Use, and $\mathrm{PU}=$ Perceived Usefulness

In the study, endogenous variables $\mathrm{CI}$ has $0.495 \mathrm{R}^{2}$ value, PU has 0.716 and PEU has 0.633 which is considered as moderate (Hair et al. 2014).

\section{Results and Discussion}

Efficiency has a positive relationship with perceived usefulness and perceived ease of use and also has a positive direct relationship with the perceived usefulness and perceived ease of use. Efficiency has a stronger significant relationship with perceived ease of use $(\beta=.52)$ compared to perceived usefulness $(\beta=.37)$, which means efficiency will contribute more towards perceived usefulness than perceived ease of use. Laukkanen and Mika (2007) noted that efficiency is vital for mobile banking and, according to Laukkanen and Lauronen (2005) for services consumption like location-free access and the ability to react immediately to the services. Anckar and D'Incau (2002) indicated efficiency needs (e.g. productivity) are required for $\mathrm{m}$-commerce to deliver special customer value to consumers. Therefore, efficiency is an important factor for delivering both usefulness and ease of use for single platform E-payment systems.

The design has a positive relationship with perceived usefulness and perceived ease of use and also has a positive direct relationship with the perceived usefulness and perceived ease of use. There isn't much difference for the design significant relationship with perceived usefulness $(\beta=.45)$ and perceived ease of use $(\beta=.38)$. The design depends on both the perceived usefulness and the perceived ease of use as shown in previous studies (Davis, 1989; Ahn, Ryu, and Han, 2004; Lin and Hsieh, 2006). Therefore, the design should be considered imperative in determining perceived usefulness and perceived ease of use.

Perceived enjoyment has a direct significant relationship with perceived usefulness but it's quite low at (.12). The positive significant relationships between perceived enjoyment with perceived usefulness are supported by previous studies (Yi and Hwang, 2003; Lai 2014; Lai 
and Zainal, 2015). Furthermore, the significant relationship for perceived enjoyment and consumers' intention to use the system are also supported (Van der Heijden, 2003; Shen, 2012; Cheema et al, 2013; Lai, 2014; Lai and Zainal, 2015). Thus, perceived enjoyment could be mediated by perceived usefulness as well as a direct relationship on perceived consumers' intention to use the single platform e-payment system.

SEM analysis showed a significant positive relationship between perceived ease of use and perceived usefulness and it was the strongest predictor of usefulness with a path coefficient of 0.78. Consistent with the previous studies, perceived usefulness is found to be influenced by perceived ease of use (Davis et al., 1989; Venkatesh and Davis 2000; Henderson and Divett, 2003; Wong and Teo, 2009). When consumers' perceived a single platform E-payment system is easy to use, their perception of the single platform E-payment system is useful too.

These results indicate that perceived usefulness and perceived ease of use contribute $72 \%$ and $63 \%$ respectively towards consumers' intention to use the single platform payment system. The explanatory power $\mathrm{R}^{2}$ score of consumers' intention to use due to perceived usefulness and perceived ease of use variables is .50. According to Cohen (1998), the explanatory power $\mathrm{R}^{2}$ scores was decoded as small $(\geq .01)$, medium $(\geq .09)$, or large $(\geq .25)$. Thus, the results showed that the single platform E-payment system has a very high perception of usefulness and ease of use and moderate consumers' intention to use by the consumers' respondents. The results of explanatory power $\left(\mathrm{R}^{2}\right)$ were the same as the findings of Yi, Jackson, Park, and Probst (2006). Thus, the consumers' intention to use is significant at $50 \%$. It showed that $50 \%$ of consumers will use the single platform E-payment system in this study. The study, therefore, establishes the roles of efficiency, design, enjoyment, perceived usefulness and perceived ease of use positioning in determining consumers' intentions to use the single platform E-payment system. Organizations providing E-payment solutions should be able to promote and facilitate the implementation of consumers' intention to use the single platform E-payment system with the suggested factors.

\subsection{Marketing and Management Implication}

In recruiting and retaining customers, marketers and management can use efficiency, design and enjoyment perspectives in an attempt to offer better services in various levels and ways with the consumers (Cheema et al, 2013; Lai and Zainal, 2014, 2015; Lai, 2007, 2016). The advantage of perceived ease of use and perceived usefulness make them a great way to offer good products/services and encourage consumers' intention to use (Davis, 1989; Kim, Mirusmonov and Lee, 2010; Lai, 2016). Furthermore, the results from the demographic respondents showed a good respond of $50 \%$ of them are infavour to use single platform E-payment. Thus, the marketing management personal shall target these particular consumers' and provide them with single platform E-payment incentives to encourage usage of E-payment while management personal shall provide support to ensure the operation and end to end E-payment provide consumers will the good experience.

\subsection{Limitation and further study}

One limitation of using online survey is reaching target audiences who have Internet or mobile data access only. The data also represents the Malaysian context and might not be 
relevant in another region. The data was collected at one point of time and may change over time due to greater experience and advancement of E-payment technologies. Therefore, future study should be expanded to non-internet users using traditional survey method where information can assist management to target non-Internet users. This study can be replicated in another region as well and use a longitudinal study to examine the Internet and Mobile e-payment with incentives or gamification and consumers' intention to use at various points of time.

\section{Conclusion}

In conclusion, the empirical results from this research suggest that convenience and security can lead to increase in the usage of consumers' intention to use a single platform E-payment system. Therefore, efficiency, design, and enjoyment should be taken into consideration when designing a single platform E-payment system in order to increase the consumers' intention to use. The empirical results suggested that by having the enjoyment to single platform E-payment can encourage the use of E-payment in this research. Thus, further research and longitudinal research is requiring for single platform E-payment approach that might still be at the infancy stage.

\section{References}

Anderson, J. C., \& Gerbing, D. W. (1988). Structural Equation Modeling in Practice: A Review and Recommended Two-Step Approach. Psychological Bulletin, 103(3), 411-423.

Anderson, R. E., \& Srinivasan, S. S. (2003). E-Satisfaction and E-Loyalty: A Contingency Framework. Psychology and Marketing, 20(2), 123-138.

Babin, B. J., Darden, W. R., \& Griffin, M. (1994). Work and/or Fun: Measuring Hedonic and Utilitarian Shopping Value. Journal of Consumer Research, 20, 644-656.

Berry, L. L., Seiders, K., \& Grewal, D. (2002). Understanding Service Convenience. Journal of Marketing, 66(3), 1-17.

Bezovski, Z. (2016). The Future of the Mobile Payment as Electronic Payment System. European Journal of Business and Management, 8(8), 127-132.

Bryne, B.M. (2010). Structural Equation Modeling with AMOS: Basic concepts, applications, and programming. Routledge.

Chang, C. C., Yan, C. F., \& Tseng, J. S. (2012). Perceived Convenience in an Extended Technology Acceptance Model: Mobile Technology and English Learning for College students. Australasian Journal of Educational Technology, 28(5), 809-826.

Chin, W. W. 2010. How to write up and report PLS analyses. In V. Esposito Vinzi, W. W. Chin, J. Henseler, \& H. Wang (Ed.), Handbook of partial least squares: Concepts, methods and application. pp. 645-689. New York, NY: Springer

Cho, Y. C., \& Sagynov, E. (2015). Exploring Factors that Affect Usefulness, Ease of Use, Trust, and Purchase Intention in the Online Environment. International Journal of Management \& Information Systems, 19(1), 21-36. 
Cohen, J. (1988). Statistical Power Analysis for the Behavioral Sciences (2nd ed.). Hillsdale, NJ: Lawrence Erlbaum Associates.

Colby, C. L., \& Parasuraman, A. (2003). Technology Still Matters. Marketing Management, 12(4), 28-33.

Davis, F. D. (1989). Perceived usefulness, perceived ease of use, and user acceptance of information technology. MIS Quarterly, 13(3), 319-340.

Davis, F. D., Bogozzi, R., P., \& Warshaw, P., R. (1989). User Acceptance of Computer Technology: A Comparison of Two Theoretical Models. Management Science, 35(8), 982-1003.

Davis, F.D. (1986). A Technology Acceptance Model for Empirically Testing New End-User Information Systems: Theory and Results. Massachusetts, United States: Sloan School of Management, Massachusetts Institute of Technology.

Dewan and Chen, 2005 "Mobile payment adoption in the US: A cross-industry, cross platform solution," Journal of Information Privacy and Security, (1:2), pp. 4 - 25

Eastin, M. S. (2002). Diffusion of E-commerce: An Analysis of the Adoption of Four E-Commerce Activities. Telematics and Informatics, 19(3), 251-267.

Fornell, C. G., \& Larcker, D. F. (1981). Evaluating Structural Equation Models with Unobservable Variables and Measurement Error. Journal of Marketing Research, 18(1), $39-50$.

Gefen, D., Straub, D. W., \& Boudreau, M. C. (2000). Structural Equation Modeling and Regression: Guidelines for Research Practice. Communications of the Association for Information Systems, 4(7), 1-70

Gold, A. H., Malhotra, A., \& Segars, A. H. (2001). Knowledge Management: An Organizational Capabilities Perspective. Journal of Management, 18(1), 185-214.

Hair, Joe F., Hult, G.Tomas., Ringle, Christian M. \& Sarstedt, M. 2014.A Primer on Partial Least Squares Structural Equation Modeling ( PLS-SEM).SAGE Publication, United State Of America.

Hair, Joe F., Hult, G.Tomas., Ringle, Christian M. \& Sarstedt, M. 2016.A Primer on Partial Least Squares Structural Equation Modeling 2 Ed. ( PLS-SEM).SAGE Publication , United State Of America.

Hair, J. F., Hult, G. T. M., Ringle, C. M., \& Sarstedt, M. (2017). A Primer on Partial Least Squares Structural Equation Modeling (PLS-SEM) (2nd ed.). Thousand Oakes,CA: Sage.

Hair J.F, Ringle CM, Sarstedt M (2011) PLS-SEM: indeed a silver bullet. J Market Theory Prac 19(2):139-152

Harris, H., Guru, B. K., \& Avvari, M. V. (2011). Evidence of firms' perceptions toward Electronic Payment Systems (EPS) in Malaysia. International Journal of Business and Information, 6(2), 226. 
Harrison, R., Scheela, W, P C, Lai, Vivekarajah, S. Beyond institutional voids and the middle income trap? The emerging business angel market in Malaysia, Asia Pacific Journal of Management. September 2017, 1-27

Henseler, J., Ringle, C. M. \& Sarstedt, M. (2015). A New Criterion for Assessing Discriminant Validity in Variance-based Structural Equation Modeling. Journal of the Academy of Marketing Science, 43(1), 115-135.

Henseler, J. Ringle, C.M. \& Sinkovics, R.R. 2009. The use of partial least squares path modeling in international marketing. Advances in International Marketing, 20, 277-319, doi:10.1108/S1474-7979(2009)0000020014.

Hirschman, E. C., \& Holbrook, M. B. (1982). Hedonic Consumption: Emerging Concepts, Methods and Propositions. Journal of Marketing, 46(3), 92-101.

Hossain, M. M. \& Prybutok, V. R. (2008). Consumer Acceptance of RFID Technology: An Exploratory Study. IEEE Transactions on Engineering Management, 55(2), 316-328.

Hu, L., \& Bentler, P. M. (1999). Cutoff Criteria for Fit Indexes in Covariance Structure Analysis: Conventional Criteria versus New Alternatives. Structural Equation Modeling, 6(1), 1-55.

Hulland, J. 1999. Use of partial least squares (PLS) in strategic management research: a review of four recent studies. Strategic Management Journal 20: 195-204.

Jackson, C.M., Chow, S., \& Leitch, R.A. (1997). Toward an Understanding of the Behavioral Intention to Use an Information System. Decision Sciences, 28 (2), 357-389.

Jahangir, N., \& Begum, N. (2008). The Role of Perceived Usefulness, Perceived Ease of Use, Security and Privacy, and Customer Attitude to Engender Customer Adaptation in the Context of Electronic Banking. African Journal of Business Management, 2(2), 32-40.

Jarvenpaa, S.L., Tractinsky, N. \& Vitale, M. (2000). Consumer trust in an Internet store. Information Technology and Management, 1(1/2), 45-71.

Javalgi, R. G., Martin, C. L., \& Todd, P. R. (2004). The Export of E-Services in the Age of Technology Transformation: Challenges and Implications for International Service Providers. Journal of Services Marketing, 18(7), 560-573.

Johnson, T. J., \& Kaye, B. K. (2002). Webelievability: A path model examining how convenience and reliance predict online credibility. Journalism \& Mass Communication Quarterly, 79(3), 619-642.

Kim, C., Tao, W., Shin, N., \& Kim, K. S. (2010). An empirical study of customers' perceptions of security and trust in e-payment systems. Electronic commerce research and applications, 9(1), 84-95.

Kim, C., Mirusmonov, M and Lee, I., (2010) "An empirical examination of factors influencing the intention to use mobile payment," Computers in Human Behavior, (26:3), pp. $310-322$. 
Kline, R. B. (2011). Principles and Practice of Structural Equation Modeling. New York: Guilford Press.

Lai P. C (2006). The significant of E-business and knowledge-based Customer Relationship in the E-market Place Environment. INTI Journal, 2 (1) 552-559.

Lai, P. C. (2007). The Chip Technology Management Implication in the Era of Globalization: Malaysian Consumers' Perspective, Asia Pacific Business Review, 3(1), 91-96

Lai P. C. (2010). E-business and E-banking. Japan Society for Software Science and Technology, Itech research group.

Lai, P. C. "Cashless, Cardless, Contactless and Convenience of MySIM," GlobalCLAS Technology (2013).

Lai, P. C. (2014). Factors influencing consumers' intention to use single platform E-payment. UNITEN

Lai, P. C. SMART LIVING for SMART CITIES @ the palm of your hand, ResearchAsia (2015).

Lai P. C. \& Ahmad, Z. A. (2015). Perceived Enjoyment of Malaysian consumers' intention to use a single platform E-payment. SHS Web of Conferences 18, 1-9

Lai P. C. \& Zainal A. A., (2015). Consumers' Intention to Use a Single Platform E-Payment System: A Study Among Malaysian Internet and Mobile Banking Users. Journal of Internet Banking and Commerce. (20) (1) 1-13

Lai P. C. \& Zainal A.A, (2015). Perceived Risk as an Extension to TAM Model: Consumers' Intention To Use A Single Platform E-Payment. Australia Journal Basic and Applied Science, 9(2): 323-330.

Lai, P. C. SMART HEALTHCARE @ the palm of our hand, ResearchAsia (2016).

Lai, P. C. (2016) Design and Security impact on consumers' intention to use single platform E-payment, Interdisciplinary Information Sciences, 22 (1), 111-122

Lai, P. C. (2017). The literature review of technology adoption models and theories for the novelty technology. Journal of Information Systems and Technology Management, 14 (1), Jan/Apr., 21-38

Lai, P C, Scheela, W, (2018) Convergence of technology in the E-commerce World and Venture Capital Landscape: South East Asia, Global Entrepreneurship and New Venture Creation in the Sharing Economy. IGI-Global, 149-168

Lai, P. C. (2018), Single platform E-payment Consumers' intention to use. Journal of Information Technology Management. 29 (2), 22-28

Lai, P. C. (2018), Security as an extension to TAM Model: Consumers' intention to use a single platform E-payment System. Asia Pacific Journal of Management Research and Innovation 13 (3-4), 110-119 
Lai, P. C., (2018), Research, Innovation and Development Strategic Planning for Intellectual Property Management, Economic Alternatives. 12 (3), 303-310

Lai, P. C., (2018), Research Methodology for novelty technology, Journal of Information Systems and Technology Management 15, 1-18

Lai, P. C., (2019) Factors That Influence the tourists' or Potential Tourists' Intention to Visit and the Contribution to the Corporate Social Responsibility Strategy for Eco-Tourism. International Journal of Tourism and Hospitality Management in the Digital Age. 3 (2), 1-21

Lai, PC, EBH Toh, AA Alkhrabsheh, (2019) Empirical Study of Single Platform E-Payment in South East Asia, Strategies and Tools for Managing Connected Consumers. IGI Global. 252-278

Laukkanen, T., \& Mika, P. (2007) "Mobile banking innovators and early adopters: How they differ from other online users?.” Journal of Financial Services Marketing, (13:2), pp. 86-94.

Li, C. F. (2013). The Revised Technology Acceptance Model and the Impact of Individual Differences in Assessing Internet Banking Use in Taiwan. International Journal of Business and Information, 8(1), 96-119.

Lin, J. and Hsieh, P., (2006) "The role of technology readiness in customers' perception and adoption of self-service technologies," International Journal of Service Industry Management, 17, pp. 497-517.

Lu, Y., Zhou, T., \& Wang, B. (2009). Exploring Chinese Users' Acceptance of Instant Messaging Using the Theory of Planned Behavior, the Technology Acceptance Model, and the Flow Theory. Computers in Human Behavior, 25(1), 29-39.

MacKenzie, S.B.,Podsakoff, P.M., \& Podsakoff, N.P.2011.Construct Measurement and Validity Assessment in Behavioral Research: Integrating New and Existing Techniques. MIS Quarterly 35(2): 293-334.

Moon, J. W., \& Kim, Y. G. (2001). Extending the TAM for a World-Wide-Web Context. Information and Management, 38(4), 217-230.

Munoz-Leiva, F., Luque-Martínez, T., \& Sánchez-Fernández, J. (2010). How to Improve Trust toward Electronic Banking. Online Information Review, 34(6), 907-934.

Özkan, S., Bindusara, G., \& Hackney, R. (2010). Facilitating the Adoption of E-Payment Systems: Theoretical Constructs and Empirical Analysis. Journal of enterprise information management, 23(3), 305-325.

Park, S. Y. (2009). An Analysis of the Technology Acceptance Model in Understanding University Students' Behavioral Intention to use E-Learning. Journal of Educational Technology \& Society, 12(3), 150-162.

Qiu, L., \& Li, D. (2008). Applying TAM in B2C E-Commerce Research: An Extended Model. Tsinghua Science \& Technology, 13(3), 265-272.

Ramayah, T., \& Ignatius, J. (2005). Impact of perceived usefulness, perceived ease of use and 
perceived enjoyment on intention to shop online. ICFAI Journal of Systems Management, 3(3), 36-51.

Riemenschneider, C. K., Harrison, D. A., \& Mykytyn, P. P. (2003). Understanding IT Adoption Decisions in Small Business: Integrating Current Theories. Information \& Management, 40(4), 269-285.

Ringle C. M., Wende, S., \& Becker, J. M. (2015). SmartPLS 3. www.smartpls.com

Siau, K., Sheng, H., Nah, F., \& Davis, S. (2004). A Qualitative Investigation on Consumer Trust in Mobile Commerce. International Journal of Electronic Business, 2(3), 283-300.

Tang, J.-t. E., \& Chiang, C. (2009, June, 4-6). Perceived Innovativeness, Perceived Convenience and TAM: Effects on Mobile Knowledge Management. Paper presented at the 2009 Third International Conference on Multimedia and Ubiquitous Engineering, Qingdao, China.

Taylor, S., \& Todd, P.A. (1995). Understanding Information Technology Usage: A Test of Competing Models. Information Systems Research, 6(2), 144-176.

Venkatesh, V., \& Davis, F. D. (2000). A Theoretical Extension of the Technology Acceptance Model: Four Longitudinal Field Studies. Management Science, 46(2), 186-204.

Wei, D., Shuo Z., Luo, G., Chen, Z., \& Ling X. (2011). Analyze on Mobile Payment Based on RFID, In Proceedings of Environmental Sciences, 10, 950 - 955

Wortley, D. J., Lai, P. C., (2017) The Impact of Disruptive Enabling Technologies on Creative Education, 3rd International Conference on Creative Education, Mar 3-4

Yoon, C., \& Kim, S. (2007). Convenience and TAM in a Ubiquitous Computing Environment: The Case of Wireless LAN. Electronic Commerce Research and Applications, 6(1), 102-112.

\section{Copyright Disclaimer}

Copyright reserved by the author(s).

This article is an open-access article distributed under the terms and conditions of the Creative Commons Attribution license (http://creativecommons.org/licenses/by/3.0/). 